\title{
LOW COST WIRELESS SENSOR NETWORK FOR GRAIN STORAGE MONITORING SYSTEM
}

\author{
Nandita D. Gargelwar \\ Department of Electronics and Communication, \\ Ballarpur Institute of Technology Ballarpur, India
}

\author{
Prof. Sunil V. Kuntawar \\ Department of Electronics and Communication, \\ Ballarpur Institute of Technology Ballarpur, India
}

\begin{abstract}
A Grain Storage can be a very suitable application of this interaction technology, where all the information related to monitoring and control can be accessed over the internet. In this work various devices and sensors are connected in a wireless sensor network within a Godown, shops, and home etc. and then all these data is send to cloud through a master node. Wireless Sensor Networks (WSNs) can have high demands for real-time data transmission and processing, but this is often constrained by limited resources. Cloud Computing can act as the backend for WSNs to provide processing and storage on demand. A generic architecture to support the integration of sensors with the Cloud. It uses a lightweight component model and dynamic proxy-based approach to connect sensors to the Cloud. The feasibility of this approach is evaluated experimentally. Agriculture industry faces different losses both before and during harvest of grains due to lack of technology usage. In fact the greatest and considerable amount of food is wasted during storage of grains. Hence, there is a need to improve the storage facilities of grains to maintain its quality and quantity efficiently in order to reduce food as well as financial loss. An efficient storage system can ensure the grain's quality by controlling and monitoring environment related factors, such as temperature, light, humidity, pests and hygiene. The technique will measure the level of grains inside an efficient level sensor and monitor the environment in silos through environmental sensors and then recorded parameters will be sent periodically to the main computing device and will be displayed automatically on the display. The user can access this data on any mobile device. An app has been developed for android platform supporting devices to demonstrate the concept.
\end{abstract}

Keywords: Grain Storage, Wireless Sensor, Monitoring System

\section{INTRODUCTION}

Recent research interests in studying food wastage have taken priority in various countries for improving food security and the sustainability of food systems. The problem of food wastage is approached in two main perspectives, namely that due to environmental conditions and the other associated with consumption factors. Food wastage takes place throughout various stages of the food supply chain, right from farm production, during processing, packing, transportation, at wholesale market, retailers, and consumption. Hence, different measurements and lack of standards in data collection make it difficult to estimate and compare the food wastage among various countries. While it is difficult to arrive at an accurate estimate, reports indicate that food wastage globally amounts to about one-third of the food produced. It is estimated that about US\$1 trillion is lost globally towards food wastage. In many low-income and developing countries, poor storage conditions and lack of appropriate storage facilities contribute considerably towards food wastage. In developing countries like China, high food wastage takes place in farm households where more than 50 percent of grain is stored, and studies indicate this is about the same level as the food wastage in developed countries. Although globally the agriculture industry faces different losses both before and during harvest of grains, the greatest and considerable wastage occurs during storage. For a sustainable development of agriculture with reduced financial loss, there is a need to improve the storage facilities of grains to maintain its quality and quantity efficiently. A good storage system using information technologies can ensure the grain's quality by controlling and monitoring impending factors, like temperature, light, humidity, pests and hygiene. Hence, in this paper we focus on developing a smart solution as an intervention for food wastage, in particular for efficient monitoring of grain storage. Traditional storage structures for grains were mainly adopted as protection from pests for a very short period and hence were not constructed of good quality. Recent development of more affordable storage solutions such as hermetic storage technology can avoid wastage due to pests as their airtight containers absorb oxygen progressively resulting in nonsurvival of pests. Another factor to preserve the quality of grains is the adoption of appropriate temperature control conditions. Even with traditional systems adopting different air-tight bulk bins for grain storage, grain damage occurred due to excessive temperature, humidity and pressure of air through the grain heap. In countries with humid and tropical climate, the lack of drying technology is the main reason for grain damage. The two-stage grain drying technology reduces the grain moisture content to a safe storage level. Therefore, there is a need to develop an intelligent, automatic and realtime measuring and controlling system for efficient grain storage. Hence, by adopting smart solutions that optimize a 
combination of such storage conditions intelligently would help in measuring and monitoring the quality of the grains and preserving them for longer periods in their storage. Such systems are important also due to scarcity of labor, cost efficiency, and high productivity. In this paper, a smart automatic monitoring and controlling system is proposed by leveraging the potentials of CPSs. The system is will make use of sensing of the temperature humidity and other affecting factors in the storage bin in order to reduce grain wastage during storage, provide a reliable, cost-effective and efficient grain quality monitoring system during grain storage, and finally provide a solution applicable to similar problems such as controlling the pest during grain storage with required extensions.

\section{PROPOSED WORK}

\section{Proposed System Architecture}

The system architecture for Grain storage must fulfill the requirements of measuring processing instrumented data, and monitoring storage application. Our approach utilizes microcontroller-enabled sensors for measuring microcontroller-enabled actuators for monitoring grain storage appliances in the front end. The whole data will be store on the cloud which can be monitored using mobile phone or through login into web server.

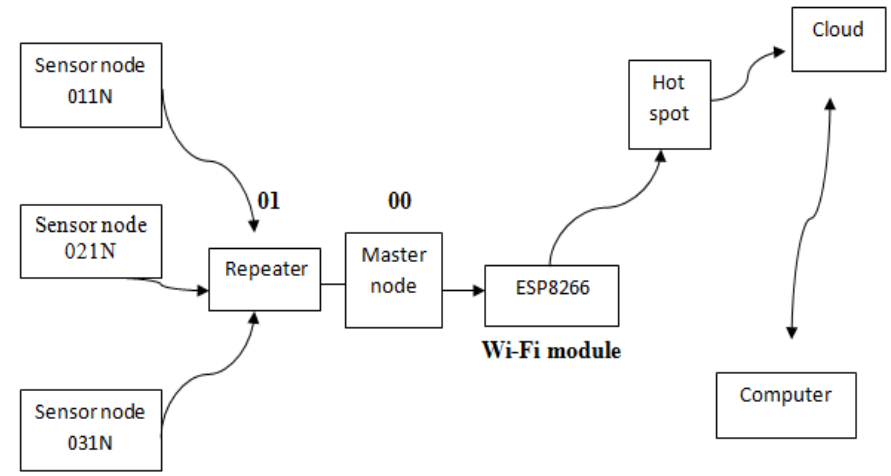

Figure 1:-. Block Representation of Sensor Node

As mentioned in the above figure, the system comprises of a Arduino Controller which will be kept at Godown. The sensors we are using are temperature sensor, humidity Sensors, dust Sensor, weight sensor, UV sensor which will be connected to the Arduino Controller which will update it on the cloud. Wi-Fi controller mounted on Arduino Controller will enable the system to get connected through internet and the web server where the data is updated frequently. These whole system could be monitored using Mobile phone and Login Web Server.

\section{Working}

- Sensor way, sensor unit, and transmitter in a wireless sensor network used, all sensors like temperature, humidity, dust sensor are connected to the ADC to the microcontroller At mega 328 transmitter to transmit and then receive to the transceiver NRF 24L01 Radio and at the same way UV rays, weight sensor collected to the ADC to the microcontroller At mega 328 transmitter unit transmit to the receiver NRF 24L01 Radio.

- Atmega 328 controller are complete sensing unit called as transmitter.

- Addressing mode, Node (011) as a temperature and humidity sensor, Node (021) as a weight and UV sensor and Node (031) as a Dust sensor node transmit to the repeater at Node $(00)$.

- Repeater (00) transmits the collected data to the master node (11). Node (00) is a transceiver.

- In repeater block not connected to the any type of sensor because it repeats type of information repeat to the receiver NRF24L01.

- Master node sends the collected data to cloud and then display the result on laptop.

- Relay through two fans is connected like warm air blower and cold air blower.

When we required we add extra Node if they are possible.

\section{Sensor Node}

The sensor nodes are developed using Arduino Nano as the controller and NRF24L01 as the transceivers. The nodes can be configured in star as well tree topology. A sensor node can send as well as receive data. Arduino Nano contains Atmega328 microcontroller it has 8-channel 10 bit ADC, which can be used to interface eight different analog sensors. It has 23 general multiplexed IOs which can be used for relay control as per requirement.

\section{Flow Chart (Sensor Node)}

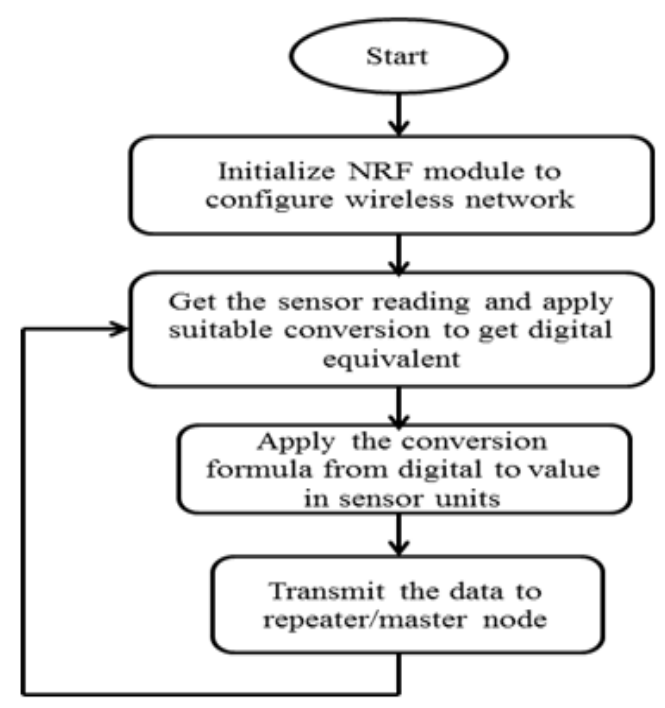

Figure 2. Sensor Node 


\section{Algorithm 1 (SENSOR NODE)}

1. Initialize the NRF24L01 wireless module with the address of the repeater/master node to send or receive data.

2. Get the sensor reading and apply suitable conversion to get digital equivalent.

3. Apply the standard conversion formula to the obtained digital value to convert it to actual sensor value in proper units.

4. Send this converted value to the repeater/master node.

5. Wait for some time for other nodes to send data. Repeat from step 2 .

\section{Repeater}

A repeater consists of Arduino Nano as controller and NRF24L01 as the transceivers. A repeater is configured to receive data from different child nodes and send it the other repeater or master node.

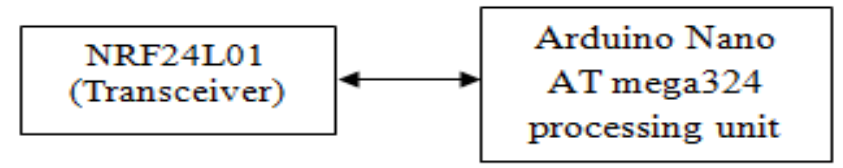

Figure 3: Block Diagram of Repeater

Flow chart: (Repeater)

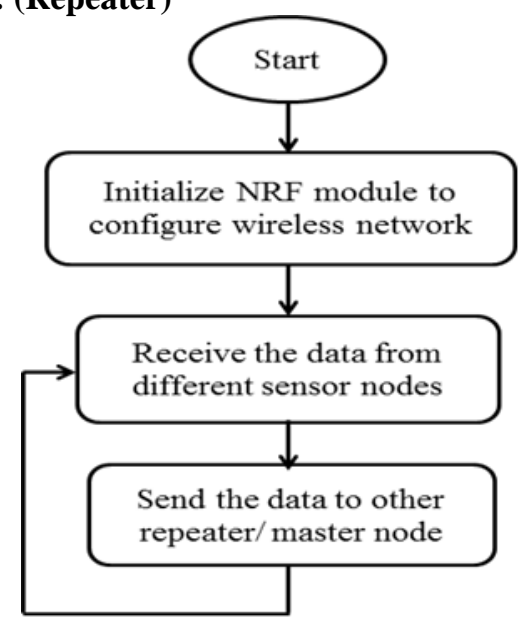

Figure 4. Repeater

Algorithm 2(Repeater Node)

1. Initialize the NRF24L01 wireless module to receive data from child nodes.

2. Initialize the NRF24L01 wireless module with the address of the repeater/master node to send data.

3. Wait to receive data from any child node.

4. Send the received data to other repeater/master node.

5. Repeat from step 3 .

\section{Master Node}

The master node also uses the Arduino Nano as the controller along with NRF24L01 as transceiver. A master node has ESP8266 for Wi-Fi connectivity with the help of this it can send all the collected data from the nodes to the cloud. A master node can send as well receive data.

The master node also uses the Arduino Nano as the controller along with NRF24L01 as transceiver. A master node has ESP8266 for Wi-Fi connectivity to send data to cloud.

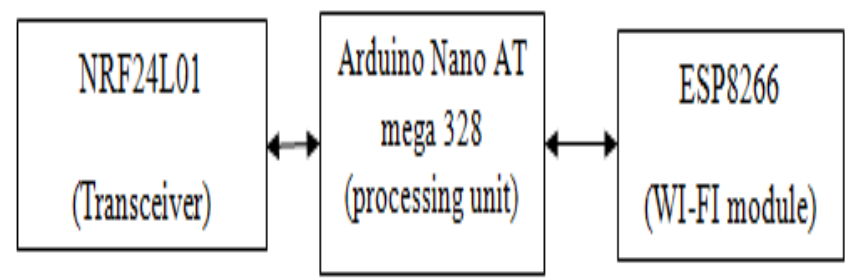

Figure 5: Block Diagram of Master Node

ESPS266

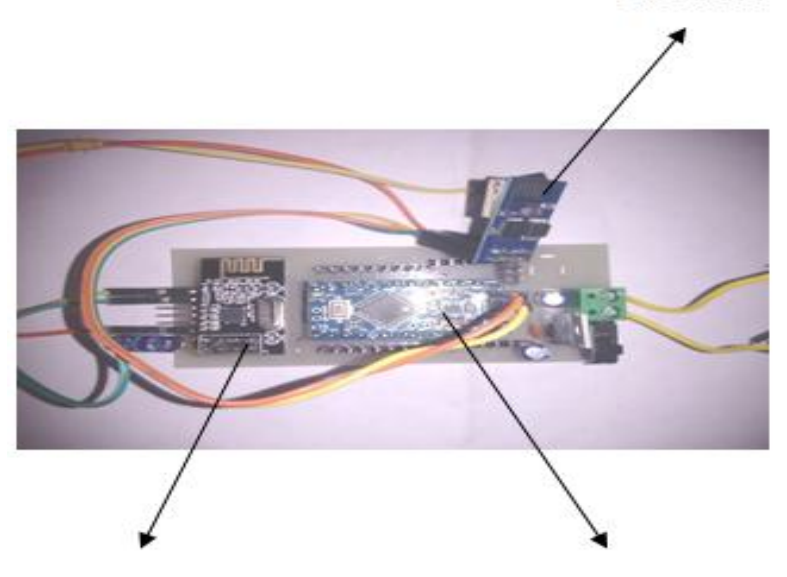

NRF24L01

Arduino Nano

Figure 6: Circuit Diagram of Master Node

\section{Flow Chart (Master Node)}




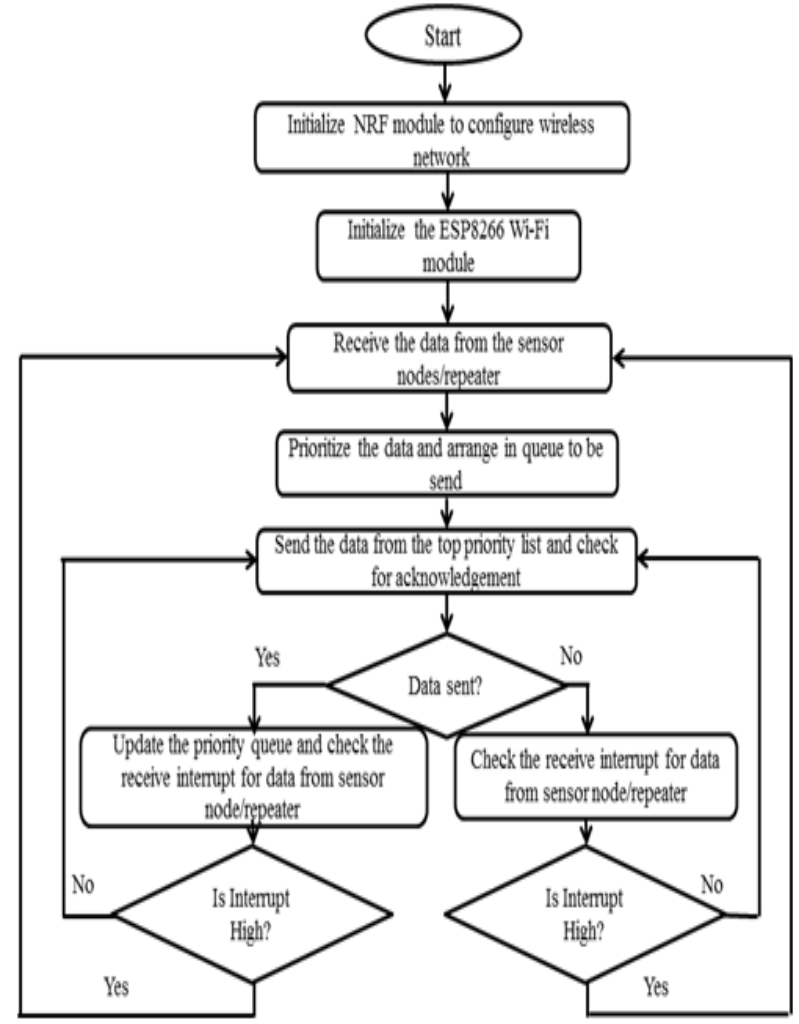

Figure 7: Master Node

Algorithm 3 (Master Node)

1. Initialize the NRF24L01 wireless module to receive data from child nodes/repeaters.

2. Initialize the ESP8266 Wi-Fi module to connect to a specified secured network.

3. Wait for receive interrupt for data from any child node/repeaters.

4. Receive the data from the child node/repeater.

5. Prepare a priority queue of the received data to send to cloud.

6. Connect to the cloud with the secured API key to the required channel.

7. Send the data with top priority to the cloud.

8. Check for acknowledgement, if data is send correctly move to next step else move to step 11 .

9. Update the priority queue and check for receive interrupt for data from any child node/repeaters.

10. If new data is received move to step 4 else move to step 6 .

11. Check for receive interrupt for data from any child node/repeaters.

12. If new data is received move to step 4 else move to step 6 .

\section{Implementations}

Wireless Sensor Network

In the experiment of Grain Storage based on IoT the sensor data must be updated on the cloud frequently hence to send the data from the each node it requires a internet gateway i.e. a Wi-Fi module or Ethernet module. But it is not possible to connect the outside sensors like sensors connected in the garden to get connected to the internet router placed inside house, also if we connect Wi-Fi module or Ethernet module to the every controller, the would increase on very higher side. So here decided to connect the all sensors in the local network using low cost frequency modules to the controller and form a start/ mesh network.

So with the help of newly launched NRF24L01 (a low cost 2.4 $\mathrm{GHz}$ transceiver) a low cost and low power Wireless sensor network is achieved. Here the star topology is used to connect all the sensors to the master gateway node. Each node having single or multiple sensors connected on it. The brain of the every sensor node is arduino based microcontroller platform. So here the low cost arduino nano is used. The nodes are battery powered and when not in use they turns into sleep mode so the power consumption is very low. The basic system architecture of the NRF24L01 is mentioned below.

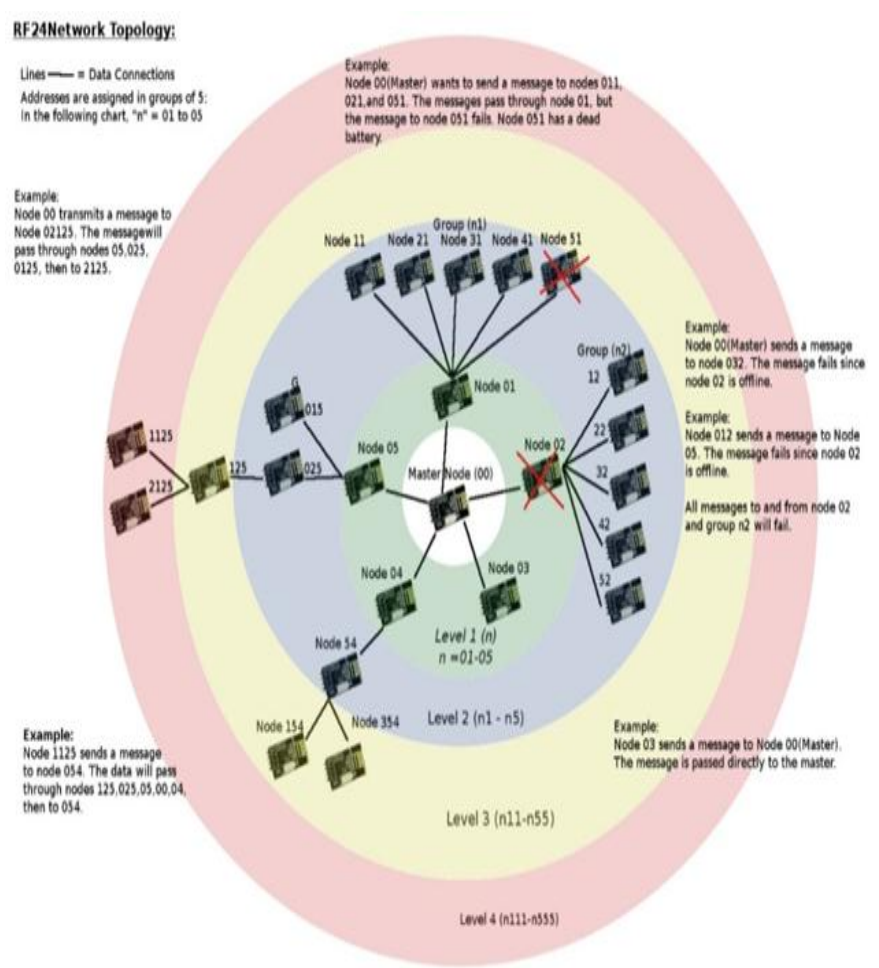

Figure 8: Star Topology for wireless sensor network using NRF24L01

\section{Tuning Overview}

The NRF24L01 radio modules are generally only capable of either sending or receiving data at any given time, but have built-in auto-retry mechanisms to prevent the loss of data. These values are adjusted automatically by the library on startup, but can be further adjusted to reduce data loss, and 


\section{International Journal of Engineering Applied Sciences and Technology, 2019 \\ Vol. 4, Issue 4, ISSN No. 2455-2143, Pages 242-250 \\ Published Online August 2019 in IJEAST (http://www.ijeast.com)}

thus increase throughput of the network. This page is intended to provide a general overview of its operation within the context of the network library, and provide guidance for adjusting these values.

\section{Auto-Retry Timing}

The core radio library provides the functionality of adjusting the internal auto-retry interval of the radio modules. In the network configuration, the radios can be set to automatically retry failed transmissions at intervals ranging anywhere from 500 us $(.5 \mathrm{~ms})$ up to $4000 \mathrm{us}(4 \mathrm{~ms})$. When operating any number of radios larger than two, it is important to stagger the assigned intervals, to prevent the radios from interfering with each other at the radio frequency (RF) layer. The library should provide fairly good working values, as it simply staggers the assigned values within groups of radios in direct communication. This value can be set manually by calling radio. set Retries $(X, 15)$; and adjusting the value of $X$ from 1 to 15 (steps of 250us).

\section{Auto-Retry Count and Extended Timeouts}

The core radio library also provides the ability to adjust the internal auto-retry count of the radio modules. The default setting is 15 automatic retries per payload, and can be extended by configuring the network. tx timeout variable. This default retry count should generally be left at 15 , as per the example in the above section. An interval/retry setting of (15, 15) will provide 15 retrys at intervals of $4 \mathrm{~ms}$, taking up to $60 \mathrm{~ms}$ per payload. The library now provides staggered timeout periods by default, but they can also be adjusted on a per-node basis. The tx timeout variable is used to extend the retry count to a defined duration in milliseconds. See the network. tx timeout variable. Timeout periods of extended duration (500+) will generally not help when payloads are failing due to data collisions, it will only extend the duration of the errors. Extended duration timeouts should generally only be configured on leaf nodes that do not receive data, or on a dualheaded node.

\section{Hardware Used}

The hardware components used in this project for different modules are as follows
1) NODE MCU ESP8266 (Wi-Fi-module)
2) Relay
3) Capacitor $(10 u F)$
4) DHT 11 Sensor
5) Voltage Regulator
6) LM 358 IC
7) ATMEGA 328 Microcontroller
8) LM 7805
9) LED
10) LM 35
11) NRF24L01
12) GP2Y1010AU0F

\section{Software Used}

\section{BLYNK APP}

Android Mobile Application Development using Blynk App Inventor

Blynk is a Platform with iOS and Android apps to control Arduino, Raspberry $\mathrm{Pi}$ and the likes over the Internet. It's a digital dashboard where you can build a graphic interface for your project by simply dragging and dropping widgets. It's really simple to set everything up and you'll start tinkering in less than 5 mins. Blynk is not tied to some specific board or shield. Instead, it's supporting hardware of your choice. Whether your Arduino or Raspberry Pi is linked to the Internet over Wi-Fi, Ethernet or this new ESP8266 chip, Blynk will get you online and ready for the Internet of Your Things.

\section{THINGSPEAK}

All the data collected by the master is continuously send to the cloud. The cloud has been created on www.thingspeak.com. The information is kept and stored on the cloud and can be viewed by the user as and when required.

\section{Wireless Sensor Network}

\section{RESULT}

After experimentation of all the modules is designed. And with the help of these modules the tiny sensor nodes have developed. These node sends the data to the master node in time/event fashion and the master is updating these all the sensor data on the Thingspeak cloud frequently. So the Data is now available for the user to access from the remote location.

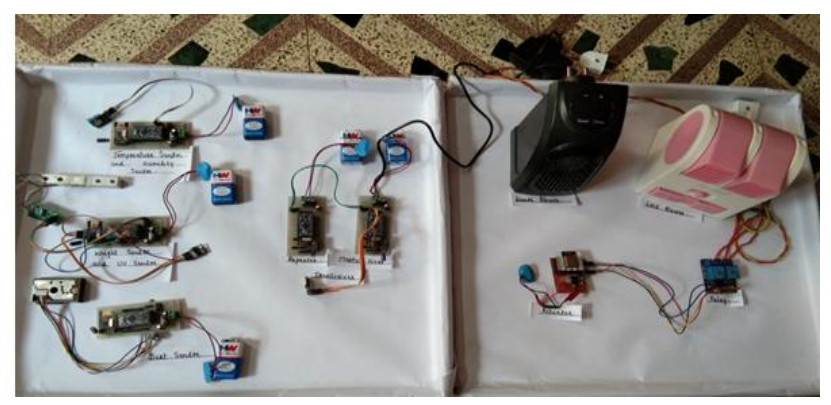

Figure 9: Final Implementation of Sensor Nodes in WSN Fashion

\section{Data Visualization on Thing speak Cloud}

Here the data of each sensor is updating on the Things peak cloud so that the same can be seen by the user. Then data can be in two format i. Public ii. Private. When the data is in the public format, there is facility for every user to see all the sensor parameters every time. But when the format is Private then user has provided with API key to access the particular register channels of Thing speak cloud. Here the experiment is in $R \& D$ so the data is publically open to everyone. In Thing 


\section{International Journal of Engineering Applied Sciences and Technology, 2019 \\ Vol. 4, Issue 4, ISSN No. 2455-2143, Pages 242-250 \\ Published Online August 2019 in IJEAST (http://www.ijeast.com)}

speak cloud each user can open several numbers of Channels but to each channel they can upload 8 (eight) sensor parameters called as field data. These field data can be seen in the graphical format using internal support.

\section{Temperature and Humidity}

Temperature sensors LM35 is chosen since LM35 provides reliable accurate surrounding temperature directly in ${ }^{\circ} \mathrm{C}$ according output voltage. These sensors are analog in nature which senses surrounding temperature produces output voltage in $\mathrm{mV}$ proportional to surrounding temperature, so it is easy to take accurate readings by connecting to development boards. It can measure temperature ranges from $-55^{\circ} \mathrm{C}$ to 150 ${ }^{\circ} \mathrm{C}$. The LM-35 is used as temperature sensor which is a precision integrated circuit temperature sensor, calibrated directly in ${ }^{\circ}$ Celsius (Centigrade).Temperature sensor is connected to "channel 0" of port A of PIC microcontroller. Humidity sensor is connected to "channel 1" of port A of PIC microcontroller. The sensor output is a variable voltage with respect to humidity level and expressed in terms of $\%$. In normal condition the humidity will be around $50 \%$ to $70 \%$. Here, we have to set the minimum humidity and maximum humidity values.

Here the Humidity and temperature can be measured by the help of DHT11 sensor which is connected to the microcontroller. The controller processes the data and sends to the master after every 2 minutes of intervals. It can measure temperature from $0-50{ }^{\circ} \mathrm{C}$ with an accuracy of $\pm 2{ }^{\circ} \mathrm{C}$ and relative humidity ranging from $20-95 \%$ with an accuracy of $\pm 5 \%$. Unit of temperature is ${ }^{\circ} \mathrm{C}$, Unit of humidity is $\mathrm{g} / \mathrm{m}^{3}$.

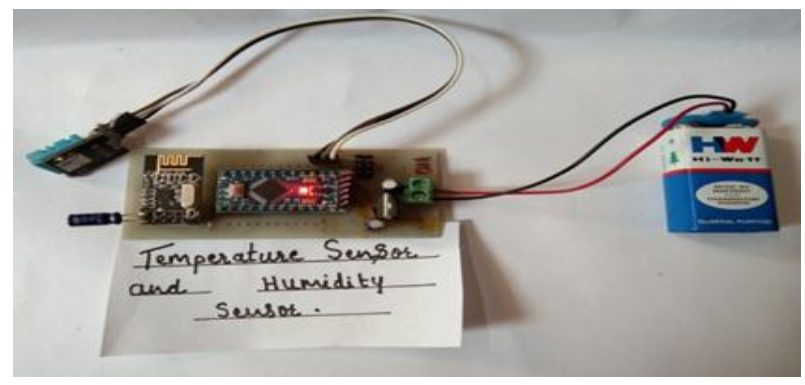

Figure 10:- Sensor Node for Humidity and Temperature

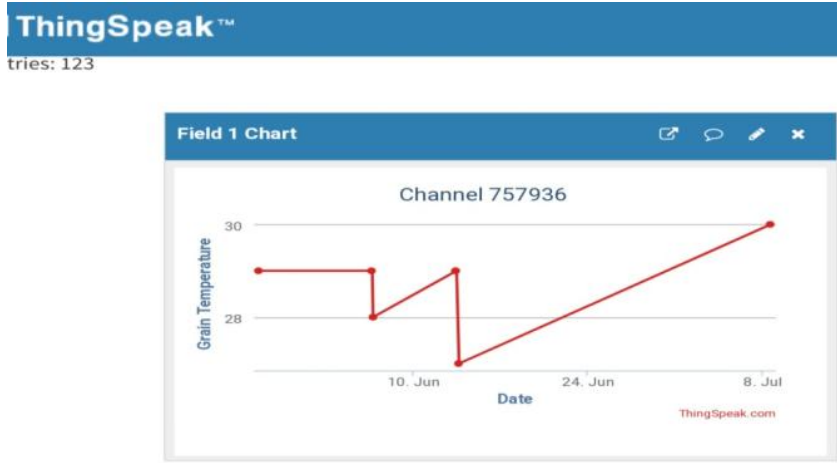

\section{ThingSpeak}

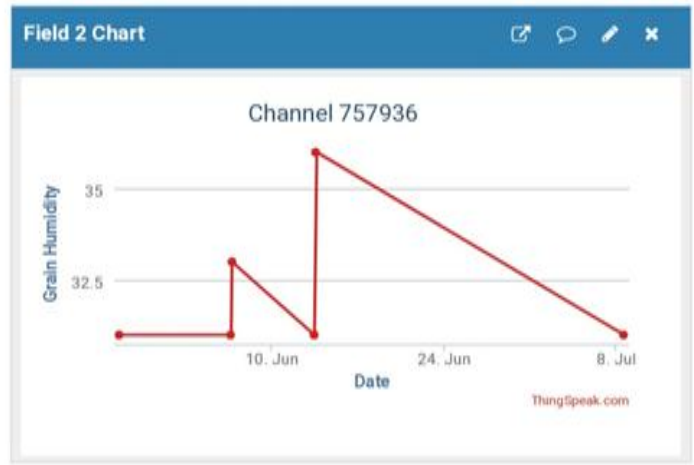

Figure 11: Temperature and Humidity Data on Channel Field $1 \& 2$

\section{Weight and UV sensor}

A load cell is a transducer that is used to create an electrical signal whose magnitude is directly proportional to the force being measured. The various load cell types include hydraulic, pneumatic, and strain gauge. A load cell is a sensor or a transducer that converts a load or force acting on it into an electronic signal. When weight is applied, the strain changes the electrical resistance of the gauges in proportion to the load. Other load cells are fading into obscurity, as strain gauge load cells continue to increase their accuracy and lower their unit costs. 


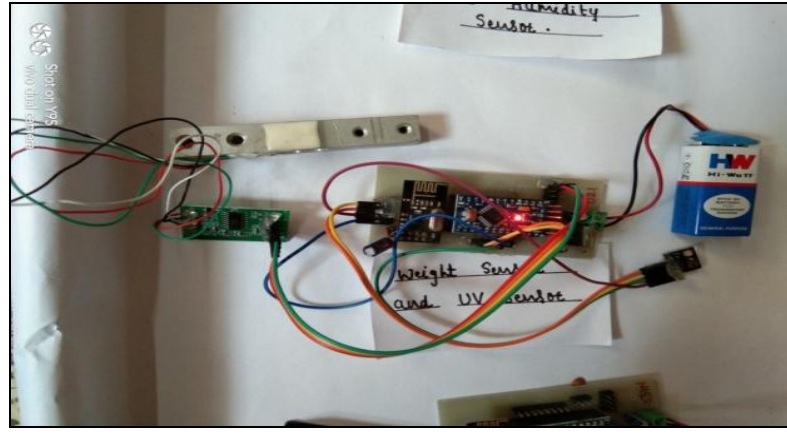

Fig 12: sensor node for weight and UV sensor

emitting diode and a phototransistor are diagonally arranged into this device, to allow it to detect the reflected light of dust in air. It integrates an internal infrared emitting diode (IRED) to detect the reflected light of dust in air and generate an output voltage proportional to dust density so as to measure dust and smoke concentration. Here the dust sensor can be sense the dust particles. Which is connected to the arduino at mega 328 microcontroller? Dust sensor sends the data to the master node through the repeater after 2 min of interval. Unit of dust sensor is $\mu \mathrm{g} / \mathrm{m}^{3}$
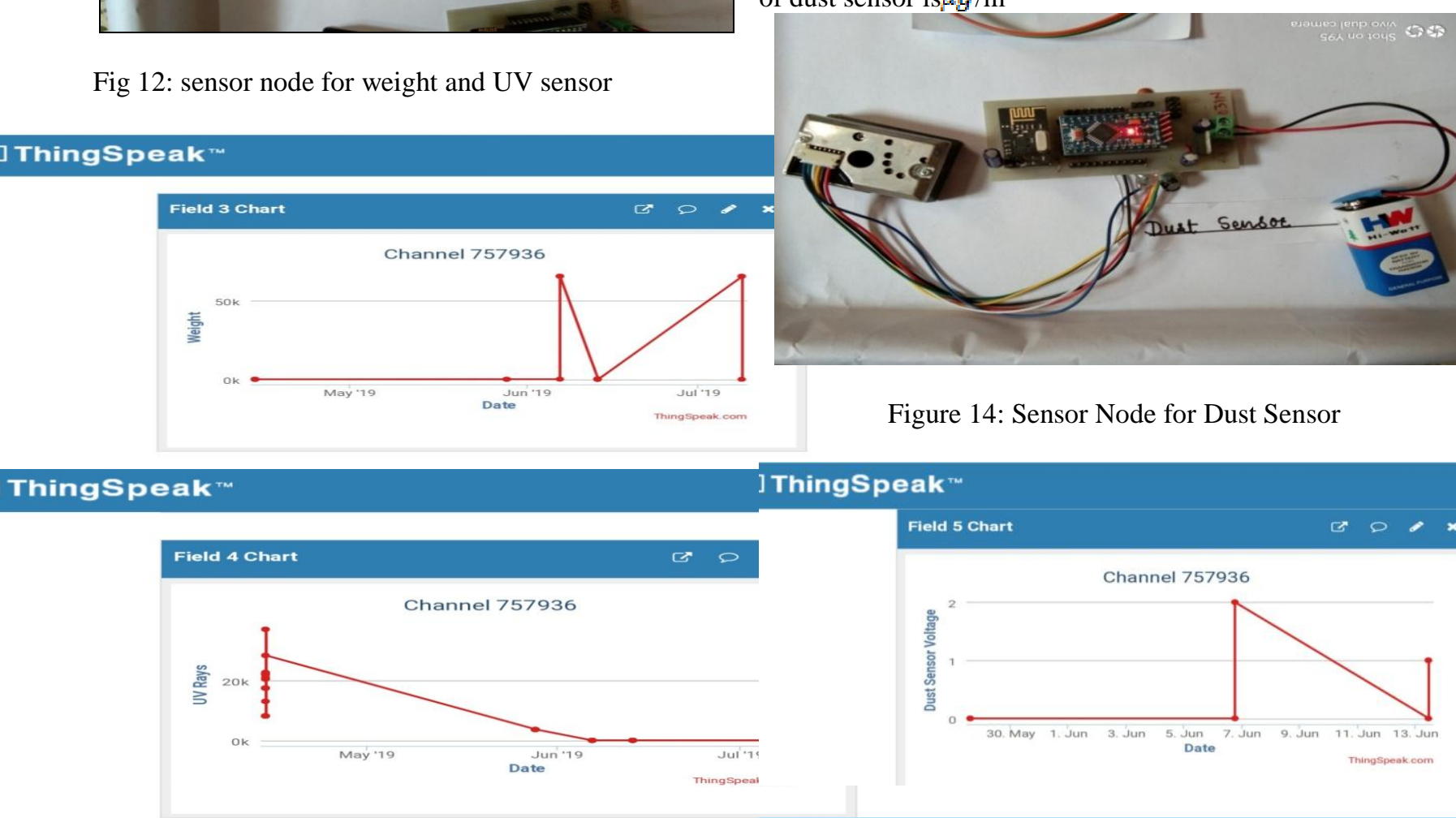

Figure 13. Weights and UV Data on Channel Field $3 \& 4$

UV sensor measures the power or intensity of incident ultraviolet (UV) radiation. This form of electromagnetic radiation has shorter wavelengths than visible radiation, but is still longer than x-rays. UV sensors are used for determining exposure to ultraviolet radiation in laboratory or environmental settings. Here the same process is applied on weight and UV sensor. In weight sensor, any type of weight is applied like $1 \mathrm{~kg}$ of sugar or $1 \mathrm{~kg}$ of wheat bag, which is connected to the arduino at mega 328 microcontrollers. Weight sensor sends the data to the master node through repeater and same UV sensor send the data to the master node through repeater. Unit of Weight sensor is force, and Unit of dust sensor is $\mu g / m 3$.

\section{Dust sensor}

This module is a dust sensing system based on the sensor GP2Y1010AU0F designed to sense dust particles. An infrared

\section{ThingSpeak}

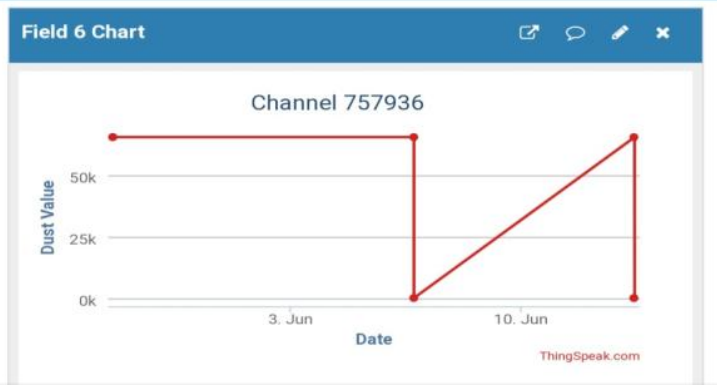

Figure 15: Dust Voltage and Value Data on Channel Field 5 \& 6

\section{Power Consumption}

Table 5.1: Power Consumption

\begin{tabular}{|l|l|l|l|l|}
\hline $\begin{array}{l}\text { Sr. } \\
\text { no. }\end{array}$ & Module & Standby & $\begin{array}{l}\text { Power } \\
\text { down }\end{array}$ & Active \\
\hline
\end{tabular}


International Journal of Engineering Applied Sciences and Technology, 2019

Vol. 4, Issue 4, ISSN No. 2455-2143, Pages 242-250

Published Online August 2019 in IJEAST (http://www.ijeast.com)

\begin{tabular}{|c|c|c|c|c|}
\hline 1 & NRF24L01 & $26 \mu \mathrm{A}$ & $900 \mu \mathrm{A}$ & $<13.5 \mathrm{~mA}$ \\
\hline 2 & ESP8266 & $5 \mu \mathrm{A}$ & $5 \mu \mathrm{A}$ & $\begin{array}{l}<103 / 275 \mathrm{MA} \\
(\max \mathrm{Rx} / \mathrm{Tx})\end{array}$ \\
\hline 3 & $\begin{array}{l}\text { ATmega } \\
328\end{array}$ & $\begin{array}{l}0.5 \mathrm{ma} @ \\
1 \mathrm{MHz} \\
3.3 \mathrm{~V}\end{array}$ & $\begin{array}{l}\frac{0.2}{\mu A @ 1 M H z\}} \\
3.3 \mathrm{~V}\end{array}$ & $>1 \mathrm{Ma}$ \\
\hline 4 & DHT11 & $100 \mu \mathrm{A}$ & $100 \mu \mathrm{A}$ & $0.2 \mathrm{ma}$ (average) \\
\hline 5 & LM & -- & -- & $\begin{array}{lr}\text { Less } & \text { than } \\
158 \mu A @ @ & 5 \mathrm{~V}, \\
125^{\circ} \mathrm{C} & \\
\end{array}$ \\
\hline
\end{tabular}

between devices with minimal resource and power consumption. After initially studying the operation of the radio modules and reviewing the details in the data sheet, I was convinced that the modules could perform much faster. Further research into the additional library forks, blog posts, and countless hours of testing revealed that the modules can be very sensitive to the timing of things. I also discovered a number of bugs and/or issues that reliability was improved over previous iterations of the library. By using this methodology there are some key features achieved which are mentioned as below:

Table 5.2 Conversation Table

\begin{tabular}{|l|l|l|}
\hline $\begin{array}{l}\text { Sr. } \\
\text { NO. }\end{array}$ & Sensor & $\begin{array}{l}\text { Interface and Conversion } \\
\text { method }\end{array}$ \\
\hline 1 & Temperature Sensor & $\begin{array}{l}\text { Analog Interface [ (ADC } \\
\text { value) *3300 / 1024 ) - 500 ] / } \\
10 \\
\text { Temperature in Celsius }\end{array}$ \\
\hline 2 & Humidity Sensor & $\begin{array}{l}\text { Sensor sends actual values } \\
\text { through 1-wire protocol } \\
\text { Relative humidity in } \\
\text { percentage, Temperature in } \\
\text { Celsius }\end{array}$ \\
\hline 3 & Weight Sensor & $\begin{array}{l}\text { Maximum weight 5kg, } \\
\text { VouT }=5.0 \mathrm{Mv}\end{array}$ \\
\hline 4 & UV Sensor & $5 \mathrm{~V}$ to 3.3V power supply \\
\hline 5 & Dust Sensor & $5 \mathrm{~V}$ power supply \\
\hline
\end{tabular}

- The cost of the complete project reduced due to the use of the low cost NRF24L01 Transceiver instead of ZigBee.

- The Throughput of the NRF24L01 is remains same as that of the ZigBee.

- The size of the sensor node reduced.

- The star topology is perfectly achieved.

In future, we can include biological sensor for better detection of contaminants in water and can install the system in several locations for high spatiotemporal coverage. In future we can use more such module which will cover more area and can be able to use for general purpose application. In future we can add more creativity in the module which can also implemented easily using chartbot. The Platform of the Iot is the very vast area so as per the present development of this project there is very large scope of modifications in this project.

\section{CONCLUSION \& FUTURE SCOPE}

\section{REFERENCES}

The conclusion of the project is that Grain storage means to store the grains in godown, shops or home. Grain storage is to increase the quality of grains. but Sometimes the quality of the grain becomes degrades in such case, the advantage of my project is that, there are certain sensors like temperature, humidity, UV, weight, dust sensor are to be activated on that place. They can sense easily and know the current quality of the grains. So in this case we can take action on it. If the grains is dry then we applied the cold cooler then the temperature become stable, and when the atmosphere become humid then we applied warm cooler. Because of that, it is increase the quality of the grains. The complete design and development of intelligent assistant control systems by using blynk app. It considered successfully because all IOT devices can be controlled by using smartphone and chatbots. Development in the field of IoT has been phenomenal in recent times. Similarly, Chatbot systems are also becoming more intelligent and sophisticated as the days progress. By using this technologies a common device can be turned into an intelligent devices, with domestic control through chatbots and IOT; this can be achieved with a low budget and resources available in the majority of storage around the world.NRF24L01 radio modules are very inexpensive and provide a robust interface for transferring data wirelessly

[1] Sazia Parvin, Amjad Gawanmeh, Sitalakshmi Venkatraman (2018) "Optimised Sensor Based Smart System for Efficient Monitoring of Grain Storage" IEEE.

[2] Ranjitha A S, Priyanka H Wadeyar, Ragini D C, Ranjitha M N, Chetan B V, (2018) Granary Management System Using, IJRTI | Volume 3, Issue 6 | ISSN: 2456-3315.

[3] K.GOPAVANITHA S.NAGARAJU (2017), "A Low Cost System for Real Time Water Quality Monitoring and Controlling using IoT" (ICECDS).

[4] Kavya P, Pallavi K N, Shwetha M N, Swetha K, Mrs. Jayasri B S, (2017) " Use of Smart Sensor \& IoT to Monitor the Preservation of Food Grains at Warehouse", vol. 2, no. 6, (pp 449-454).

[5] Vinayaka H, Roopa J (2016) "Intelligent System for Monitoring and Controlling Grain Condition Based on ARM 7 Processor (IJLTEMAS) Volume V, Issue VII, July | ISSN 2278-2540.

[6] Partha Pratim Ray*, Shubham Pradhan, Roshan Kumar Sharma, Animesh Rasaily, Abhinav Swaraj, Ashish Pradhan. (2016) "loT Based Fruit Quality Measurement System" Online International Conference on Green Engineering and Technologies (IC-GET). 
[7] Vinay Sambhaji Suryawanshi, Mahesh S. Kumbhar, (2014) "Real Time Monitoring \& Controlling System for Food Grain Storage" Volume 3, Special Issue 3, March International Conference on Innovations in Engineering and Technology (ICIET').

[8] Congcong. Li*, Yanxia Guo and Jingren Zhou, (2014) " Study and design of the agricultural informationization model based on internet of things," Journal of Chemical and Pharmaceutical Research, 6(6): (1625-1630). 